\title{
Retrieval practice can eliminate list method directed forgetting
}

\author{
Magdalena Abel $^{1} \cdot$ Karl-Heinz T. Bäuml $^{1}$
}

Published online: 19 August 2015

(C) Psychonomic Society, Inc. 2015

\begin{abstract}
It has recently been shown that retrieval practice can reduce memories' susceptibility to interference, like retroactive and proactive interference. In this study, we therefore examined whether retrieval practice can also reduce list method directed forgetting, a form of intentional forgetting that presupposes interference. In each of two experiments, subjects successively studied two lists of items. After studying each single list, subjects restudied the list items to enhance learning, or they were asked to recall the items. Following restudy or retrieval practice of list 1 items, subjects were cued to either forget the list or remember it for an upcoming final test. Experiment 1 employed a free-recall and Experiment 2 a cued-recall procedure on the final memory test. In both experiments, directed forgetting was present in the restudy condition but was absent in the retrieval-practice condition, indicating that retrieval practice can reduce or even eliminate this form of forgetting. The results are consistent with the view that retrieval practice enhances list segregation processes. Such processes may reduce interference between lists and thus reduce directed forgetting.
\end{abstract}

Keywords Retrieval practice - Directed forgetting · Interference $\cdot$ List segregation

Karl-Heinz T. Bäuml

karl-heinz.baeuml@ur.de

1 Department of Experimental Psychology, Regensburg University, 93040 Regensburg, Germany
It is well documented in the memory literature that memory performance can benefit from retrieval practice. Particularly prominent is the finding that retrieval practice in comparison to restudy of previously encoded material can boost long-term retention and reduce time-dependent forgetting, which is often referred to as the testing effect (e.g., Roediger $\&$ Karpicke, 2006). However, there are further benefits of retrieval practice. For instance, retrieval practice in comparison to restudy can improve organization of newly acquired knowledge (e.g., Zaromb \& Roediger, 2010), enhance its transfer to other study contexts (e.g., Butler, 2010), and potentiate subsequent learning (e.g., Arnold \& McDermott, 2013). Retrieval practice can also reduce the susceptibility of memories to interference, both retroactive and proactive interference, a result that is of direct relevance for the present study (for a list of ten benefits of retrieval practice, see Roediger, Putnam, \& Smith, 2011).

Retroactive interference refers to the finding that the subsequent study of further nontarget information can impair memory for previously studied target information (Müller \& Pilzecker, 1900). Halamish and Bjork (2011) recently examined the role of retrieval practice for retroactive interference. They asked subjects to initially study a target list of paired associates, and then restudy one half of the associates but do retrieval practice on the other. Retrieval practice was conducted by presenting the stimulus words of each single paired associate and asking subjects to generate the appropriate response word from the list. Subsequently, subjects were asked to study another (nontarget) list of paired associates, which contained the same stimulus terms as the original target list. On the final memory test, stimulus words were presented again and subjects were asked to recall the response words of the target list. Retrieval practice in comparison to restudy reduced retroactive inter- 
ference and led to better memory performance for the target items. Potts and Shanks (2012) extended the finding and showed that the beneficial influence of retrieval practice on retroactive interference can even persist when original learning, retrieval practice, and interfering learning are separated by delays of $24 \mathrm{~h}$ (for another demonstration that retrieval practice can reduce retroactive interference, see Abel \& Bäuml, 2014).

Proactive interference describes the finding that the preceding study of further nontarget material can impair memory for subsequently studied target information (Underwood 1957). To examine the role of retrieval practice for proactive interference, Szpunar, McDermott, and Roediger (2008) applied a multiple-list paradigm, in which subjects successively studied four nontarget lists and a final target list in anticipation of a final cumulative recall test. All subjects were tested immediately on the target list. One group of subjects was also tested immediately on the four nontarget lists, whereas another group restudied these lists, and a third group did a mathematical distractor task after each single list. Subjects who were tested immediately on the nontarget lists recalled more target items and showed fewer prior-list intrusions than subjects in the two no-testing groups, indicating that interpolated retrieval practice can insulate against proactive interference. Pastötter, Schicker, Niedernhuber, and Bäuml (2011) extended the finding by demonstrating that interpolated retrieval practice does not only improve retrieval but can also improve encoding of the single lists (for related results, see Bäuml \& Kliegl, 2013, and Weinstein, McDermott, \& Szpunar, 2011).

The finding that retrieval practice can reduce memories' susceptibility to both retroactive and proactive interference has been attributed to enhanced list segregation processes, assuming that retrieval practice can help to distinguish retrieval practiced information from interfering information (Abel \& Bäuml, 2014; Bäuml \& Kliegl, 2013; Halamish \& Bjork, 2011; Szpunar et al. 2008). Enhanced list segregation may be mediated by the production of distinct context features that are created during retrieval practice and are encoded with the retrieved items (see Karpicke, Lehman, \& Aue, 2014). Such context features may enable better discrimination of studied lists at test and thus reduce items' susceptibility to (retroactive and proactive) interference.

The finding that retrieval practice can reduce interference between lists suggests that retrieval practice can also reduce list method directed forgetting (LMDF). In the LMDF task (Bjork 1970), subjects successively study two item lists, and, between lists, receive a cue to either remember the first list for a later memory test or to forget the first list, pretending that it was presented for practice only. On the final memory test, the forget cue typically reduces recall of list 1 items and improves recall of list 2 items relative to the remember condition. The forgetting effect for list 1 is often explained by impaired access to the list's encoding context, be it by direct inhibition of the study context (Geiselman, Bjork, \& Fishman, 1983) or a mental context change between study of the two lists (Sahakyan and Kelley 2002). In contrast, the beneficial effect for list 2 has been attributed to a reduction in interference from list 1 (Geiselman et al., 1983; Sahakyan \& Kelley, 2002), with a possible additional role of improved encoding of the postcue items (Pastötter \& Bäuml, 2010; Sahakyan \& Delaney, 2003).

Interference between lists plays a critical role in LMDF and, in theoretical accounts of LMDF, is regarded a precondition for the forgetting effect to arise (Geiselman et al., 1983; Sahakyan \& Kelley, 2002). The results of previous studies support such view and reported no forgetting of list 1 items when interference between lists was experimentally reduced, i.e., when there were strong associative relationships between the items of the two lists (Conway, Harries, Noyes, Racsmany, \& Frankish, 2000; Sahakyan \& Goodmon, 2007), when list 1 items were taken from a different semantic category than the items of list 2 (Lehman \& Malmberg, 2011), and when the two lists were presented in different study formats (Hupbach \& Sahakyan, 2014). Vice versa, the effect of the forget cue was found to be enhanced if interference was augmented by increasing the number of studied precue lists (Bäuml \& Kliegl, 2013). On the basis of these studies and the finding that retrieval practice can reduce interference between lists (Halamish \& Bjork, 2011; Szpunar et al., 2008), the suggestion arises that retrieval practice may also reduce LMDF.

Although no previous study has yet directly examined whether retrieval practice in comparison to restudy reduces LMDF, the results of two studies provide first information about the possible role of retrieval practice in LMDF. Applying a multiple-list paradigm, in which subjects successively studied five lists of items, Szpunar, McDermott, and Roediger (2007) manipulated whether (or not) subjects received initial retrieval practice for these lists and whether (or not) they were made aware of an upcoming final memory test. Initial retrieval practice enhanced finaltest performance, with more enhancement if subjects were made aware of the final test. The study also included an extra condition in which subjects received initial retrieval practice for the single lists, were not made aware of the final test, and were additionally provided cues to forget the single lists after initial retrieval practice. Relative to a matched control condition, in which subjects were not provided with any forget cues, the additional presentation of the forget cues left recall on the final cumulative 
recall test unaffected, indicating that a forget cue may no longer affect recall if lists are retrieval practiced after study.

A different indication on the possible role of retrieval practice for LMDF arises from a study by Sahakyan, Delaney, and Kelley (2004). These researchers applied the LMDF task and incorporated retrieval practice into the task to investigate the influence of self-evaluation on list 2 items. Although list 1 was not the primary target in this work, list 1 recall was analyzed as well. Whereas list 1 recall was higher when the list items were retrieval practiced after initial study in comparison to a control condition without retrieval practice, list 1 forgetting was present after retrieval practice and did not differ in size from the study-only condition, which suggests that retrieval practice may leave list 1 forgetting largely unaffected.

The results from the two previous studies thus provide mixed evidence on the possible role of retrieval practice in LMDF, with the one study suggesting that retrieval practice can reduce the influence of the forget cue (Szpunar et al., 2007), and the other study indicating that the influence of the forget cue is not affected by prior retrieval practice (Sahakyan et al., 2004). In both studies, the focus of the research was not on whether retrieval practice affects LMDF, and therefore the effects of retrieval practice on the influence of the forget cue were not compared to restudy trials. Inclusion of a restudy condition as a baseline control, however, is a sine qua non to understand the possible role of retrieval practice for LMDF (e.g., Halamish \& Bjork, 2011; Pastötter et al., 2011; Szpunar et al., 2008). The present study, therefore, revisited the issue and examined the influence of retrieval practice in LMDF by comparing the effects of retrieval practice directly with the effects of restudy trials.

The results of two experiments are reported, in each of which subjects completed the LMDF task and studied two item lists. In the restudy conditions, both lists were presented on two consecutive study cycles, whereas, in the retrieval-practice conditions, subjects received initial retrieval practice for these lists. After restudy or retrieval practice of list 1 , subjects were either cued to remember the list for an upcoming memory test, or they were cued to forget the list because it would no longer be relevant. Experiment 1 comprised a free recall test and Experiment 2 a cued recall procedure as the final memory test. Because, following theoretical accounts of LMDF, interference between lists is a precondition for LMDF to arise (Geiselman et al., 1983; Sahakyan \& Kelley, 2002), and retrieval practice, but not restudy, has been shown to reduce such interference (Halamish \& Bjork, 2011; Szpunar et al., 2008), we expected retrieval practice to reduce, or even eliminate, directed forgetting.

\section{Experiment 1}

\section{Method}

\section{Participants}

Sixty-four students enrolled at Regensburg University were recruited for the experiment ( $M=22.1$ years; range, 18 31 years). All participants spoke German as their native language.

\section{Material}

Item material consisted of two sets that each comprised two item lists. Each of the four item lists included 12 unrelated nouns that were taken from different semantic categories (Van Overschelde, Rawson, \& Dunlosky, 2004) and translated into German. Each item set was equally often used across experimental conditions; within sets, sequence of lists was counterbalanced.

\section{Design}

The experiment had a $2 \times 2$ mixed-factorial design. The factor of CUE (remember, forget) was manipulated within subjects. All subjects were asked to work on the LMDF task and to complete two experimental blocks. In one of the two blocks, they were cued to remember the first list, whereas in the other block, they were cued to forget the list. Sequence of cue conditions was counterbalanced across subjects (see Bäuml \& Samenieh, 2010, 2012; Zellner \& Bäuml, 2006). The factor of PRACTICE (restudy, retrieval practice) was manipulated between subjects, and subjects were randomly assigned to one of the two conditions. Whereas one half of the subjects were asked to recall each list after its initial study (retrieval-practice condition), for the other half the study list was reexposed for additional study (restudy condition).

\section{Procedure}

Study phase In each of two experimental blocks, subjects consecutively studied two item lists, both comprising 12 items. Items were presented one at a time, in a random order, and for $5 \mathrm{~s}$ each centrally on a computer screen. Immediately after a list's initial study cycle, subjects practiced the list. In the restudy condition, subjects were asked to study the respective items again to enhance learning. All list items were presented once more, in a random order, and for $5 \mathrm{~s}$ each. In contrast, in the retrieval-practice condition, subjects were asked to recall as many of the previously studied items as possible, and to write them down on a piece of paper. 
Subjects were given $60 \mathrm{~s}$ for this task, thereby holding the overall duration of task constant across practice conditions. In accordance with the LMDF task, subjects then received a cue to either forget or remember the first list. Cuing took place once practice of the first list was completed. When being cued to forget the first list, subjects were told that the list would not be relevant for the later memory test and that they should try to forget it and focus on the list coming up next. When being cued to remember the first list, subjects were instead warned that the list would be relevant and tested later, and that they should additionally memorize the second list coming up next. After receiving cue instructions, subjects studied and practiced the second list in exactly the same way as they learned the first list. A short distractor task was placed after list 2 encoding, and subjects were asked to work on unrelated (geographic) tasks for 3 min before the final memory test was administered.

Test phase Before testing started, subjects who had received the forget cue were debriefed and asked to remember as many of the first-list items as possible, irrespective of original cuing. Subjects were given $90 \mathrm{~s}$ to write down all list 1 items they could remember on a piece of paper. Subsequently, list 2 was tested in exactly the same way. When the first experimental block was completed, subjects were assured that the studied and tested material would not be needed for the rest of the experiment. After a short break, the second experimental block started.

\section{Results}

\section{Success rates in the retrieval-practice condition}

When recalling items after initial study in the retrievalpractice condition, subjects recalled $81.0 \%(S D=19.1)$ of list 1 items in the forget condition and $80.2 \%(S D=18.8)$ in the remember condition. Similarly, subjects recalled $78.4 \%(S D=19.8)$ of list 2 items in the forget condition and $77.6 \%(S D=19.7)$ in the remember condition. There were no significant differences in recall success between cue conditions, for both list 1 and list $2, \operatorname{ts}(31)<1.0$.

\section{List 1 recall and list 2 intrusions}

Table 1 shows mean recall rates of list 1 items and mean numbers of list 2 intrusions as a function of cue, practice condition, and list. Regarding list 1 recall, a $2 \times 2$ ANOVA with the factors of CUE (remember, forget) and PRACTICE (restudy, retrieval practice) revealed a significant main effect of CUE, $F(1,62)=4.03, M S E=.02$, $p=.049, \eta^{2}=0.06$, but no main effect of PRACTICE, $F(1,62)<1.0$. In particular, a significant interaction between the two factors arose, $F(1,62)=4.03, M S E=$ $.02, p=.049, \eta^{2}=0.06$, suggesting that type of practice affected list 1 forgetting. Indeed, whereas list 1 recall was significantly reduced in response to the forget cue in the restudy condition, $t(31)=3.22, p=.003, d=0.57$, there was no reliable difference between cue conditions in the retrieval-practice condition, $t(31)<1.0$.

Intrusions from list 2 during list 1 recall were analyzed by means of another $2 \times 2$ ANOVA. The analysis showed no main effect of CUE and no main effect of PRACTICE, $F s(1,62) \leq 1.62, M S E s \geq 0.65, p s \geq .208$, but a significant interaction between the two factors, $F(1,62)=$ $6.41, M S E=0.65, p=.014, \eta^{2}=0.09$. Consistently, a greater number of intrusion errors arose in response to the forget cue in the restudy condition, $t(31)=2.18$, $p=.037, d=0.39$, whereas no such difference was present in the retrieval-practice condition, $t(31)=1.35$, $p=.187$.

\section{List 2 recall and list 1 intrusions}

Concerning list 2 recall, no significant main effects of CUE and PRACTICE arose, and there was also no significant interaction between the two factors, all $F s(1,62) \leq 1.04$,

Table 1 Mean recall performance and mean number of intrusion errors in Experiment 1 as a function of cue (remember, forget), practice (restudy, retrieval practice), and tested list (list 1, list 2). Standard errors are displayed in parentheses

\begin{tabular}{|c|c|c|c|c|c|c|}
\hline \multirow[t]{2}{*}{ Experiment 1} & \multicolumn{3}{|c|}{ Restudy condition } & \multicolumn{3}{|c|}{ Retrieval-practice condition } \\
\hline & Remember cue & Forget cue & $\begin{array}{l}\text { L1 Forgetting / } \\
\text { L2 Enhancement }\end{array}$ & Remember cue & Forget cue & $\begin{array}{l}\text { L1 Forgetting / } \\
\text { L2 Enhancement }\end{array}$ \\
\hline L1 Recall (\% Correct) & $65.6(4.5)$ & $56.3(5.2)$ & $-9.3 \%$ & $63.5(5.5)$ & $63.5(5.5)$ & $0.0 \%$ \\
\hline Number of L2 Intrusions & $.16(.07)$ & $.63(.23)$ & & $.31(.18)$ & $.06(.04)$ & \\
\hline L2 Recall (\% Correct) & $65.4(5.1)$ & $70.6(3.7)$ & $+5.2 \%$ & $69.0(5.2)$ & $70.1(4.8)$ & $+1.1 \%$ \\
\hline Number of L1 Intrusions & $.44(.14)$ & $.75(.26)$ & & $.34(.12)$ & $.25(.13)$ & \\
\hline
\end{tabular}


$M S E s \geq .03, p s \geq .313$. Concerning list 1 intrusions, again no significant main effects of CUE and PRACTICE arose, $F s(1,62) \leq 2.00, M S E s \geq 0.45$, ps $\geq .162$. There was a marginally significant interaction between the two factors, $F(1,62)=2.95, M S E=0.45, p=.091$, $\eta^{2}=0.05$, but in none of the two practice conditions any reliable effect of cue arose, $t s(31) \leq 1.44, p s \geq .161$.

\section{Discussion}

The results of Experiment 1 show that retrieval practice can eliminate directed forgetting. While intact list 1 forgetting was observed when the single lists had been restudied, no forgetting arose when the lists were retrieval practiced. The results for the restudy condition replicate prior LMDF work, which showed that list 1 forgetting is still present after restudy cycles (Abel \& Bäuml, 2013; Sahakyan, Delaney, $\&$ Waldum, 2008). In contrast, the results for the retrieval practice condition are new and provide first direct evidence that retrieval practice can eliminate list 1 forgetting. Supporting the view, the present results also show that retrieval practice can reduce the effect of the forget cue on intrusion rates. While the present results for the restudy condition replicate a previous finding by indicating that list 2 intrusion rates can increase in response to the forget cue (Spillers \& Unsworth, 2011), the results for the retrieval-practice condition show that the effect is no longer present if retrieval practice follows initial list study.

Whereas the present results show reliable list 1 forgetting, they do not show reliable list 2 enhancement. These results replicate the findings of many recent studies, in which no list 2 enhancement arose when at test list 1 was recalled first and list 2 was recalled second (e.g., Delaney \& Sahakyan, 2007; Delaney, Nghiem, \& Waldum, 2009; Pastötter \& Bäuml, 2010; Zellner \& Bäuml, 2006), a procedure that was also chosen in the present experiment. Indeed, conducting a meta-analysis on the influence of list output order on LMDF, Pastötter, Kliegl, and Bäuml (2012) recently showed that the forget cue induces facilitation for list 2 items mainly when list 2 is tested first and shows hardly any facilitatory effect when list 2 is tested last. The present finding of no list 2 enhancement thus very likely arose due to chosen list output order.

In order to replicate the results of Experiment 1, we conducted a second experiment. Experiment 2 was largely identical to Experiment 1, but the format of the final test was changed from free recall (Experiment 1) to cued recall and the items' unique initial letters were provided as retrieval cues at test. Thus, while in Experiment 1 the test format was identical to the format during retrieval-practice cycles, in Experiment 2 there was a slight difference in format between retrieval practice and test.

\section{Experiment 2}

\section{Method}

\section{Participants}

A fresh sample of 64 students took part in the experiment ( $M=23.0$ years; range, $18-31$ years).

\section{Material}

New item material was compiled, consisting of two sets that each comprised two item lists. Each of the four item lists was made up of 15 unrelated German nouns, taken from different semantic categories (Van Overschelde et al., 2004). Within each list, items had unique initial letters. Item sets were counterbalanced across experimental conditions; within sets, sequence of lists was counterbalanced as well.

\section{Design}

The experiment had the same $2 \times 2$ mixed-factorial design as Experiment 1. The factor of CUE (remember, forget) was again manipulated within subjects, the factor of PRACTICE (restudy, retrieval practice) was manipulated between subjects.

\section{Procedure}

The procedure was largely identical to the procedure of Experiment 1 . The only exception was that the final memory test employed a cued-recall procedure. The items' unique initial letters were provided as retrieval cues, and subjects were asked to complete the cues with the studied words. Retrieval cues were presented in a random order and for 8 sec each. Subjects were asked to write down their responses on a sheet of paper. Again, list 1 was tested first and list 2 was tested last.

\section{Results}

Success rates in the retrieval-practice condition

When recalling items during retrieval practice, subjects recalled $74.6 \%$ ( $S D=20.1)$ of list 1 items in the forget condition and $76.7 \%(S D=19.5)$ in the remember condition. Furthermore, subjects recalled $74.6 \%(S D=19.0)$ of list 2 items in the forget condition and $69.4 \%(S D=21.7)$ in the remember condition. There was no significant difference in recall success between cue conditions for list $1, t(31)<1.0$, while a marginally significant difference emerged for list $2, t(31)=1.71, p=.097$. 


\section{List 1 recall and list 2 intrusions}

Table 2 shows mean recall rates of list 1 items and mean numbers of list 2 intrusions as a function of cue, practice condition, and list. Regarding list 1 recall, a $2 \times 2$ ANOVA with the factors of CUE (remember, forget) and PRACTICE (restudy, retrieval practice) revealed a significant main effect of CUE, $F(1,62)=4.34, M S E=0.04$, $p=.041, \eta^{2}=0.07$, but no main effect of PRACTICE, $F(1,62)=1.25, M S E=0.06, p=.268, \eta^{2}=0.02$. In addition, the analysis revealed a significant interaction between the two factors, $F(1,62)=5.17, M S E=0.04$, $p=.026, \eta^{2}=0.08$. List 1 recall was significantly reduced in response to the forget cue in the restudy condition, $t(31)=3.00, p=.005, d=0.53$, whereas no such effect arose in the retrieval-practice condition, $t(31)<1.0$.

Analysis of list 2 intrusions showed no significant main effects of CUE and PRACTICE, $F s(1,62) \leq 1.62, M S E s \geq$ 1.49 , $p s \geq .208$, but a significant interaction between the two factors, $F(1,62)=4.11, M S E=1.49, p=.047$, $\eta^{2}=0.06$. A marginally greater number of intrusion errors occurred in response to the forget cue in the restudy condition, $t(31)=1.79, p=.083, d=0.32$, while there was no such difference after retrieval practice, $t(31)<1.0$.

\section{List 2 recall and list 1 intrusions}

Concerning list 2 recall, no significant main effects of CUE and PRACTICE emerged, and there was also no significant interaction between the two factors, all $F s(1,62) \leq 1.64$, $M S E s \geq .02, p s \geq .205$. Similarly, concerning intrusions from list 1 during list 2 recall, no main effects and no interaction between factors arose, all $F s(1,62) \leq 1.91$, $M S E s \geq 0.72, p s \geq .172$.

\section{Discussion}

Like in Experiment 1, list 1 forgetting was present after restudy trials, but was absent after retrieval practice. Similar to Experiment 1, list 2 intrusion rates were slightly larger in response to the forget cue in the restudy condition (Spillers \& Unsworth, 2011), but not in the retrieval-practice condition. These findings confirm the results observed in Experiment 1. Recall rates after retrieval practice were lower in Experiment 2 than in Experiment 1, likely because in Experiment 2, but not in Experiment 1, final-test format differed somewhat from the format at retrieval practice. The effects of retrieval practice on list 1 forgetting, however, were not influenced by this factor. Finally, like in Experiment 1 , no reliable effect of the forget cue on list 2 recall arose. Again, this should have been caused by the chosen list output order.

\section{General discussion}

The core hypothesis of this study has been that retrieval practice may reduce or even eliminate LMDF. This hypothesis was suggested on the basis of findings showing that (i) amount of LMDF depends on amount of interference between lists (e.g., Bäuml \& Kliegl, 2013; Sahakyan \& Goodmon, 2007), and (ii) retrieval practice can reduce or even eliminate interlist interference (e.g., Halamish \& Bjork, 2011; Szpunar et al., 2008). The results of the present study support the suggested hypothesis. While in both Experiment 1 and Experiment 2 list 1 forgetting was present when subjects restudied lists after initial study, no such forgetting arose when subjects were engaged in retrieval practice. In addition, the results showed that the increase in intrusion errors in response to the forget cue in the restudy condition was no longer present in the retrievalpractice condition, thus making memory performance in the forget condition largely indistinguishable from memory performance in the remember condition when retrieval practice was induced. Although comparison of the results of Experiment 1 and Experiment 2 provides evidence for reduced recall rates when retrieval formats between practice and test differed (Experiment 2) relative to when formats were matched (Experiment 1), this effect did not influence the impact of retrieval practice on list 1 forgetting.

Table 2 Mean recall performance and mean number of intrusion errors in Experiment 1 as a function of cue (remember, forget), practice (restudy, retrieval practice), and tested list (list 1, list 2). Standard errors are displayed in parentheses

\begin{tabular}{|c|c|c|c|c|c|c|}
\hline \multirow[t]{2}{*}{ Experiment 2} & \multicolumn{3}{|c|}{ Restudy condition } & \multicolumn{3}{|c|}{ Retrieval-practice condition } \\
\hline & Remember cue & Forget cue & $\begin{array}{l}\text { L1 Forgetting / } \\
\text { L2 Enhancement }\end{array}$ & Remember cue & Forget cue & $\begin{array}{l}\text { L1 Forgetting / } \\
\text { L2 enhancement }\end{array}$ \\
\hline L1 Recall (\% Correct) & $59.4(4.3)$ & $45.0(4.1)$ & $-14.4 \%$ & $46.9(3.9)$ & $47.5(3.4)$ & $+0.6 \%$ \\
\hline Number of L2 Intrusions & $.56(.13)$ & $1.22(.41)$ & & $.63(.23)$ & $.41(.17)$ & \\
\hline L2 Recall (\% Correct) & $55.0(4.4)$ & $60.0(4.1)$ & $+5.0 \%$ & $49.8(4.4)$ & $50.8(4.6)$ & $+1.0 \%$ \\
\hline Number of L1 Intrusions & $.44(.13)$ & $.38(.13)$ & & $.78(.22)$ & $.59(.21)$ & \\
\hline
\end{tabular}


The present finding that retrieval practice reduces list 1 forgetting is consistent with the results from the previous study by Szpunar et al. (2007), who applied a multiple-list paradigm and showed that providing additional forget cues after interpolated retrieval practice does not affect memory performance on a final (unexpected) cumulative recall test. Our study transfers the observation to the classic LMDF task and in particular shows that the finding is retrieval specific, i.e., it arises after retrieval practice but is absent after restudy trials. In contrast, the present results appear less well consistent with the results of Sahakyan et al. (2004), who employed the LMDF task and found the forgetting to be present after retrieval practice. However, no restudy baseline condition was included in this prior study and mean success rates during retrieval practice were rather low (49\% vs. $77 \%$ in the present study), inducing only a small amount of recall improvement for list 1 items at test (less than $5 \%$ improvement relative to a no-practice baseline). If higher success rates during retrieval practice increase chances that retrieval practice reduces directed forgetting, then this may explain why directed forgetting was absent after retrieval practice in this study but was present in the previous one. ${ }^{1}$

Recent work has shown that retrieval practice can reduce the susceptibility of memories to interference. Corresponding evidence has arisen from studies showing that retrieval practice in comparison to restudy can reduce retrieved items' susceptibility to retroactive interference (Abel \& Bäuml, 2014; Halamish \& Bjork, 2011; Potts \& Shanks, 2012), and from studies demonstrating that, in a multiplelist paradigm, interpolated retrieval practice in comparison to restudy can insulate memories against the buildup of proactive interference (Bäuml \& Kliegl, 2013; Pastötter et al., 2011; Szpunar et al., 2008; Weinstein et al., 2011). The present study complements this prior work by indicating that, also in the LMDF task, retrieval practice can reduce interference between lists and thus reduce, or even eliminate, directed forgetting.

In the experiments of the present study, retrieval practice (or restudy) was always conducted on both list 1 and list 2 items and such retrieval practice eliminated the directed forgetting effect. An interesting question that arises from this finding is whether the absence of a directed forgetting effect in the presence of retrieval practice was the result of the fact that the first list was tested, the second list was tested, or both lists were tested. The present study was not designed to

\footnotetext{
${ }^{1}$ Employing a relatively short delay between learning and test, retrieval practice did not produce a general mnemonic advantage over restudy in the present study. This result is in line with previous work, which indicates that mnemonic benefits of retrieval practice typically arise with longer delay between learning and test (for a review, see Roediger \& Butler, 2011). It should be emphasized that, despite the absence of a general mnemonic advantage of retrieval over restudy in the present study, the results demonstrate that retrieval practice, but not restudy, eliminates directed forgetting.
}

address this issue. However, there is evidence that retrieval practice can immunize retrieved items against retroactive interference, even if the subsequently encoded interfering items are not retrieval practiced (Abel \& Bäuml, 2014; Halamish \& Bjork, 2011), and there is evidence that proactive interference for a target list can be reduced if only the previously studied nontarget items are subject to retrieval practice (Pastötter et al., 2011; Szpunar et al., 2008). These findings may suggest that retrieval practice on one of the two LMDF lists can already be sufficient to reduce, or eliminate, directed forgetting, and additional retrieval practice on the other list is not necessary to get the effect. Further work is needed to address the issue in more detail and examine directly whether retrieval practice on one of the two LMDF lists is sufficient to eliminate list 1 forgetting.

The present and previous findings support the view that retrieval practice can enhance list segregation processes and help to distinguish retrieval practiced information from other information (Abel \& Bäuml, 2014; Bäuml \& Kliegl, 2013; Halamish \& Bjork, 2011; Szpunar et al., 2008). The findings are consistent with the proposal that retrieval practice can create a distinct set of context features that are encoded with the retrieved items and thus may facilitate discrimination of studied lists at test (e.g., Karpicke et al., 2014). On the basis of such proposal, retrieval practice may reduce memories' retroactive and proactive interference and also reduce directed forgetting, which is exactly what the present results show.

Arguably, retrieval practice may eliminate directed forgetting not primarily because it reduces interlist interference but because retrieval practice serves exactly the same function as a forget cue does (see Szpunar et al., 2007). Indeed, when subjects do not anticipate a final cumulative memory test, after retrieval practice subjects may think that the practiced information is no longer needed and the list gets deactivated very similar to how the list gets deactivated in response to a forget cue (Geiselman et al., 1983; Sahakyan \& Kelley 2002). If so, retrieval practice should show the same basic effects than a forget cue does, i.e., reduce recall of the previously encoded items (e.g., list 1) and enhance recall of the subsequently encoded items (e.g., list 2). Several previous findings suggest that retrieval practice indeed enhances memory for the subsequently encoded items. For instance, both a forget cue and retrieval practice have been shown to reduce proactive interference (Bjork 1970; Szpunar et al. 2008), induce more focused memory search for subsequently encoded information (Bäuml \& Kliegl, 2013), and enhance encoding of these items (Arnold \& McDermott, 2013; Pastötter et al., 2011). However, whether retrieval practice also reduces recall of the previously encoded items is largely unclear and the present finding of lower list 1 recall after the forget cue in the restudy condition than after the remember cue in 
the retrieval-practice condition of Experiment $1(56.3 \%$ vs. $63.5 \%$ ) is even inconsistent with such a view. Future work is required to clarify this theoretical issue and examine whether retrieval "only" reduces interlist interference or is even functionally equivalent to the presentation of a forget cue.

A core assumption of theoretical accounts of LMDF is that successful LMDF presupposes the presence of interference between lists (Geiselman et al., 1983; Sahakyan \& Kelley, 2002). In line with this view, it has been shown that list 1 forgetting can be eliminated if there is a strong associative relationship between list 1 and list 2 items (Conway et al., 2000; Sahakyan \& Goodmon, 2007), or when the two lists are presented in different study formats (Hupbach \& Sahakyan, 2014). The present results add to this list of boundary conditions on LMDF by showing that retrieval practice after initial study can also eliminate list 1 forgetting. While in some of these boundary conditions, like when the items of the two lists are associatively related (Conway et al., 2000; Sahakyan \& Goodmon, 2007), integration processes may be at the heart of the reduced interference (Conway et al., 2000), in others, like when lists are presented in different study formats (Hupbach \& Sahakyan, 2014), and in the present study, enhanced list segregation processes may mediate the effect.

Research on LMDF typically distinguishes between two effects of the forget cue on memory performance, list 1 forgetting and list 2 enhancement. In this study, the focus was on list 1 forgetting and we therefore asked subjects at test to recall list 1 items first and list 2 items second. Doing so, we did not find a reliable enhancement effect for list 2 items, which is consistent with previous studies that used the same list output order (see above and Pastötter et al., 2012, for a theoretical explanation). However, if list output order was reversed and list 2 items were recalled first, the present results may well generalize to list 2 enhancement and retrieval practice reduce list 2 enhancement as well. The reason for this expectation is that list 1 forgetting and list 2 enhancement appear to be (partly) mediated by similar mechanisms and supposedly depend both on interference between lists (e.g., Geiselman et al., 1983; Sahakyan $\&$ Kelley, 2002). Future work may like to examine the issue directly.

To conclude, the results of the present study strengthen the view that retrieval practice protects memories against interference. Corresponding evidence has been reported previously by showing that retrieval practice insulates memories against the buildup of retroactive and proactive interference. The present study complements this work and shows that retrieval practice also reduces directed forgetting.
Authors' Note We thank H. L. Roediger III and one anonymous reviewer for their helpful comments on a previous version of the manuscript and T. Kraus and E. Rose for their help with data collection.

\section{References}

Abel, M., \& Bäuml, K.-H.T. (2013). Sleep can eliminate list method directed forgetting. Journal of Experimental Psychology: Learning, Memory, and Cognition, 39, 946-952.

Abel, M., \& Bäuml, K.-H.T. (2014). The roles of delay and retroactive interference in retrieval-induced forgetting. Memory \& Cognition, $42,141-150$.

Arnold, K.M., \& McDermott, K.B. (2013). Test-potentiated learning: Distinguishing between direct and indirect effects of tests. Journal of Experimental Psychology: Learning, Memory, and Cognition, 39, 940-945.

Bäuml, K.-H.T., \& Kliegl, O. (2013). The critical role of retrieval processes in release from proactive interference. Journal of Memory and Language, 68, 39-53.

Bäuml, K.-H.T., \& Samenieh, A. (2010). The two faces of memory retrieval. Psychological Science, 21, 793-795.

Bäuml, K.-H.T., \& Samenieh, A. (2012). Selective memory retrieval can impair and improve retrieval of other memories. Journal of Experimental Psychology: Learning, Memory, \& Cognition, 38, 488-494.

Bjork, R.A. (1970). Positive forgetting: The noninterference of items intentionally forgotten. Journal of Verbal Learning and Verbal Behavior, 9, 255-268.

Butler, A.C. (2010). Repeated testing produces superior transfer of learning relative to repeated studying. Journal of Experimental Psychology: Learning, Memory, and Cognition, 36, 1118-1133.

Conway, M.A., Harries, K., Noyes, J., Racsmany, M., \& Frankish, C.R. (2000). The disruption and dissolution of directed forgetting: Inhibitory control of memory. Journal of Memory \& Language, 43, 409-430.

Delaney, P.F., Nghiem, K.N., \& Waldum, E.R. (2009). The selective directed forgetting effect: Can people forget only part of a text? The Quarterly Journal of Experimental Psychology, 62, 15421550.

Delaney, P.F., \& Sahakyan, L. (2007). Unexpected costs of high working memory capacity following directed forgetting and contextual change manipulations. Memory \& Cognition, 35, 1074-1082.

Geiselman, R.E., Bjork, R.A., \& Fishman, D. (1983). Disrupted retrieval in directed forgetting: A link with posthypnotic amnesia. Journal of Experimental Psychology: General, 112, 58-72.

Halamish, V., \& Bjork, R.A. (2011). When does testing enhance retention? A distribution-based interpretation of retrieval as a memory modifier. Journal of Experimental Psychology: Learning, Memory, and Cognition, 37, 801-812.

Hupbach, A., \& Sahakyan, L. (2014). Additional boundary condition for list method directed forgetting: The effect of presentation format. Journal of Experimental Psychology: Learning, Memory, and Cognition, 40, 596-601.

Karpicke, J.D., Lehman, M., \& Aue, W.R. (2014). Retrieval-based learning: an episodic context account. In Ross, B. (Ed.), The Psychology of Learning and Motivation, (Vol. 61 pp. 237-284). San Diego: Elsevier Academic Press.

Lehman, M., \& Malmberg, K.J. (2011). Overcoming the effects of intentional forgetting. Memory \& Cognition, 39, 335-347.

Müller, G.E., \& Pilzecker, A. (1900). Experimentelle Beiträge zur Lehre vom Gedächtnis. Zeitschrift für Psychologie, 1, 1-300. 
Pastötter, B., \& Bäuml, K.-H. (2010). Amount of postcue encoding predicts amount of directed forgetting. Journal of Experimental Psychology: Learning, Memory, \& Cognition, 36, 54-65.

Pastötter, B., Kliegl, O., \& Bäuml, K.-H.T. (2012). List method directed forgetting: The forget cue improves both encoding and retrieval of postcue information. Memory \& Cognition, 40, 861873.

Pastötter, B., Schicker, S., Niedernhuber, J., \& Bäuml, K.-H.T. (2011). Retrieval during learning facilitates subsequent memory encoding. Journal of Experimental Psychology: Learning, Memory, \& Cognition, 37, 287-297.

Potts, R., \& Shanks, D.R. (2012). Can testing immunize against interference? Journal of Experimental Psychology: Learning, Memory, and Cognition, 38, 1780-1785.

Roediger, H.L.I., \& Butler, A.C. (2011). The critical role of retrieval practice in long-term retention. Trends in Cognitive Sciences, 15, 20-27.

Roediger, H.L.I., \& Karpicke, J.D. (2006). Test-enhanced learning: Taking memory tests improves long-term retention. Psychological Science, 17, 249-255.

Roediger, H.L.I., Putnam, A.L., \& Smith, M.A. (2011). Ten benefits of testing and their applications to educational practice. In Mestre, J., \& Ross, B. (Eds.), Psychology of learning and motivation: Cognition in education (pp. 1-36). Oxford: Elsevier.

Sahakyan, L., \& Delaney, P.F. (2003). Can encoding differences explain the benefits of directed forgetting in the list method paradigm? Journal of Memory and Language, 48, 195-206.

Sahakyan, L., Delaney, P.F., \& Kelley, C.M. (2004). Self-evaluation as a moderating factor of strategy change in directed forgetting benefits. Psychonomic Bulletin \& Review, 11, 131-136.

Sahakyan, L., Delaney, P.F., \& Waldum, E.R. (2008). Intentional forgetting is easier after two "shots" than after one. Journal of Experimental Psychology: Learning, Memory, and Cognition, 34, 408-414.
Sahakyan, L., \& Goodmon, L.B. (2007). The influence of directional associations on directed forgetting and interference. Journal of Experimental Psychology: Learning, Memory, and Cognition, 33, $1035-1049$.

Sahakyan, L., \& Kelley, C.M. (2002). A contextual change account of the directed forgetting effect. Journal of Experimental Psychology: Learning, Memory, and Cognition, 28, 1064-1072.

Spillers, G.J., \& Unsworth, N. (2011). Are the costs of directed forgetting due to failures of sampling or recovery? Exploring the dynamics of recall in list method directed forgetting. Memory \& Cognition, 39, 403-411.

Szpunar, K.K., McDermott, K.B., \& Roediger, H.L. (2007). Expectation of a final cumulative test enhances long-term retention. Memory \& Cognition, 35, 1007-1013.

Szpunar, K.K., McDermott, K.B., \& Roediger, H.L. (2008). Testing during study insulates against the buildup of proactive interference. Journal of Experimental Psychology: Learning, Memory, and Cognition, 34, 1392-1399.

Underwood, B.J. (1957). Interference and forgetting. Psychological Review, 64, 49-60.

Van Overschelde, J.P., Rawson, K.A., \& Dunlosky, J. (2004). Category norms: An updated and expanded version of the Battig and Montague (1969) norms. Journal of Memory and Language, 50, 289335.

Weinstein, Y., McDermott, K.B., \& Szpunar K. K. (2011). Testing protects against proactive interference in face-name learning. Psychonomic Bulletin \& Review, 18, 518-523.

Zaromb, F.M., \& Roediger, H.L. (2010). The testing effect in free recall is associated with enhanced organizational processes. Memory \& Cognition, 38, 995-1008.

Zellner, M., \& Bäuml, K. (2006). Inhibitory deficits in older adults: List method directed forgetting revisited. Journal of Experimental Psychology: Learning, Memory, and Cognition, 32, 290-300. 